\title{
On Successful Implementation of ERP Software
}

\author{
Momin Mukherjee and Sahadev Roy
}

\begin{abstract}
In this paper we discuss the reprisal importance of customization of Enterprise Resource Planning or ERP. Few important decision making factors of the ERP are also discussed here. Software customization process briefly describe here for standard ERP design. Different difficulties in ERP are analysis here. Implementation life cycle of ERP is an important consideration which also discussed here. Organization is expected to build a culture of learning within the organization. Strong sense of belonging must be there among the employees which is the key factor of successful implementation.
\end{abstract}

\section{Keywords}

Application specific software;

Database management;

Dedicated software;

Difficulties in decision-making;

Enterprise resource planning;

Implementation life cycle of ERP;

Multisite issues resolved;

Software customization.

\section{INTRODUCTION}

Business development is the most essential for any organization to achieving this organization need to have a good business development and organizational[1]. The various schemes for achieving leads, responds quickly to the leads and finally converts the leads into the customers. it is very much significant to develop a fruitful customer relationships[2] for getting repeat orders and a satisfied reference customer.

Enterprise resource planning or ERP is an application specific software, where a specific programs develop for user for industrial as well as organizations to improve their operation and reduced the wastage of valuable resources by optimized the material handling process[3]. ERP referred basically as to how to exercise and manage directorial general assets properly[4]. ERP systems is used in different kind of organization and it may be big or small[5]. Each industry will have it's their own mechanism to smoothly run their organization and one software program are design and developed for that specific field to fulfil the requirements of every specific field[6]. The standard code of the ERP may be changed or modified by the user or the developers according to the requirement of the client, which is known as customization[7]. Customization or application specific design arises after the realization of any institutions that they are in stable operation in the past few years[8]. In the customization process, externally tools and also dedicated software are used frequently[9].

Almost all tolls are required customization depending on the organization. But same type of organization has similar type of work flow. Institute or university required almost same type of ERP for student database management which is not required for industry where as tendering process almost same. Customizations are essential for incensement of the brand development with time. Now a day's ERP become an essential marketing toll to boost the customer engagement by providing them easy to access methodology.

\section{CRITICAL FACTORS FOR ERP IMPLEMENTATION}

Some factors are essentially required to analysis before ERP implementation. Before implementation of the target organizations required to proper and clear understating of the strategic goals. Data accuracy is an essential criterion for any organization[10]. Required input parameters and all possible outputs parameters are essentially must known by the development team[11]. The proper management of the processed data required the input output relationship. These relationships are only provided by the top management. The success of ERP software implementation also depends on the dedicated project management and implementation team[12]. Multisite issues must be resolved before successful coping with technical issues from ERP software of similar type of organizational sutures. Extensive education \& training and onsite modification [13] are also essential for proper utilization of ERP software.

\section{A. Rigidity of Decision-Maker}

A decision-maker may adopt a rigid stand in the form of overemphasis on past experience, over insistence on specific technique, prejudice, and so forth. He may fail to understand the dynamic need of the situation. Ultimately, he makes erroneous decisions.

\section{B. Rigidity of Decision-Maker}

In many cases, a decision-maker may have to decide between clashing priorities. For example, profit maximisation and consumer satisfaction are two priorities that are opposite to one another. He may fail to take the right decision in such a situation. 


\section{Overemphasis on a Specific Method}

Some decision-makers insist on using only a particular decision-making method(s) irrespective of the situation (type of problem, objective, data available, time limit, and so forth). The method may be inconsistent with the situation. Inconsistent method produces inconsistent results that lead to erroneous decisions.

\section{Lack of Cooperation/Support}

At times, a decision-maker is unable to solicit the necessary support from both his superior as well as subordinates. Lack of support sometimes results in poor decisions, or ineffective implementation of decisions, or both.

\section{E. Support Failure to Implement Decision}

Practical value of decision depends on its effective implementation. Sometimes, the right decisions (taken by managers) are not implemented successfully and the whole procedure of decision-making results in wasteful exercise. There are many reasons for implementation fails, such as resistance from people in the organisation, lack of necessary support from top authority, insufficient resources, fear of uncertain outcomes, and likewise.

\section{F. Subjectivity}

It implies the presence of personal bias or absence of objectivity. Right from defining the problem to implementation of decision, the whole process of decision-making is influenced by personal values, needs, perception, and attitudes. Pure objective (rational, neutral, impersonal, and fact-based) decisions are difficult to observe in practice. Subjectivity affects adversely the quality of decision-making.

\section{G. Assumptions}

Most decisions are taken under conditions of uncertainty. A decision-maker has to make assumptions about occurrence of the future events. All assumptions may not turn true. Especially, long-term assumptions are more difficult to set. To the extent the assumptions turn false, decisions suffer.

\section{H. Personal Risk}

Uncertainty of outcomes is a common problem in decision-making. Risk is an integral part of decision making and its implementation. When a decision-maker is not insulated (protected) with sufficient security for the decisions and the resulting outcomes, he hesitates to take decisions. A manager does not prefer to take decisions on his personal risk.

\section{Impact of Extraneous Factors}

Despite taking all possible precautions to ensure the prudent decisions, a decision-maker may fail due to the adverse impacts of many extraneous (external uncontrollable) factors. Government policies, international business environment, natural calamities, market trend, competition, etc., affect the outcome of decision-making.

\section{IMPLEMENTATION LIFE CYCLE}

Success of any project depends on availability of critical equipments, automation and project management ability. Relative control over the over project teams are essential for successful completion of any projects[14]. ERP software helps them to manage over these. Experience with type of environment and programming environment, language or system used

To access success in the ERP implementation vision, goals and objectives are also necessary. According to mission statement it should have some following characteristics (i) not lengthy (ii) clearly articulated, (iii) broad, but not too general, (iv) relevant and current, (v) unique, enduring and dynamic and (vi) customer orientation. Goals of the ERP software to be utilized long period of time and provide immediate and short term results. The implementation life cycle of the ERP software is (i) pre-evaluation screening, (ii) required package evaluation and project planning, (iii) demo design, (iv)gap analysis between demo ERP and original, (v) reengineering and configuration, (vi) implementation and internal team training, (vii) testing and end-user training, (viii) on site live and (ix) post implementation and modification.

\section{CONCLUSion}

Extensive education \& training and onsite modification are also essential for proper utilization of ERP software. Information is the basic input in decisionmaking. A decision-maker needs equate, reliable, relevant, and timely information to decide on any issue. Poor information leads to poor decisions. This is the major problem faced by every manager. operational excellence have many parameters namely optimizing productivity of the resources, minimizing wastages, streamline business processes, delivering excellent customer services and finally achieving quality product at an affordable cost to have competitive edge.

\section{REFERENCES}

[1] Mukherjee, K. (2016). The Psychology of the Successful Entrepreneur. International Journal of Advanced Engineering and Management, 1(1), 2532.

[2] Mukherjee, M. (2017). Entrepreneurial Judgment and Analysis for Successful Strategy Implementation. International Journal of Advanced Engineering and Management, 2(1),1-8.

[3] Loh, T. C., \& Koh, S. C. L. (2004). Critical elements for a successful enterprise resource 
planning implementation in small-and mediumsized enterprises. International Journal of Production Research, 42(17), 3433-3455.

[4] Ramesh, G. (2010). The ACE of soft skills: Attitude, communication and etiquette for success. Pearson Education India.

[5] Bernroider, E., \& Koch, S. (2001). ERP selection process in midsize and large organizations. Business Process Management Journal, 7(3), 251-257.

[6] Day, G. S. (1994). The capabilities of market-driven organizations. The Journal of Marketing, 37-52.

[7] Law, C. C., Chen, C. C., \& Wu, B. J. (2010). Managing the full ERP life-cycle: Considerations of maintenance and support requirements and IT governance practice as integral elements of the formula for successful ERP adoption. Computers in Industry, 61(3), 297-308.

[8] Peters, L., \& Saidin, H. (2000). IT and the mass customization of services: the challenge of implementation. International Journal of Information Management, 20(2), 103-119.

[9] Leseure, M. J., \& Brookes, N. J. (2004). Knowledge management benchmarks for project management. Journal of knowledge management, 8(1), 103-116.

[10] Bacharach, S. B. (1989). Organizational theories: Some criteria for evaluation. Academy of management review, 14(4), 496-515.

[11] Eppinger, S. D., Whitney, D. E., Smith, R. P., \& Gebala, D. A. (1994). A model-based method for organizing tasks in product development. Research in engineering design, 6(1), 1-13.

[12] Umble, E. J., Haft, R. R., \& Umble, M. M. (2003). Enterprise resource planning: Implementation procedures and critical success factors. European journal of operational research, 146(2), 241-257.

[13] Dowlatshahi*, S. (2005). Strategic success factors in enterprise resource-planning design and implementation: a case-study approach. International journal of production research, 43(18), 3745-3771.

[14] Bonner, J. M., Ruekert, R. W., \& Walker, O. C. (2002). Upper management control of new product development projects and project performance. Journal of Product Innovation Management, 19(3), 233-245.

\section{Momin Mukherjee}

Dept. of Management \& Humanities, NIT Arunachal Pradesh, India Email: mmukherjee964@gmail.com

Sahadev Roy

Dept. of ECE, NIT Arunachal Pradesh, India

Email: sahadevroy@gmail.com

Authors Details: 